\title{
Os textos que um texto esconde...
}

\author{
Sérgio de Freitas Oliveira*
}

\begin{abstract}
Resumo
Leitura e escrita são atividades interativas, uma vez que quem escreve o faz com um propósito: dizer algo a alguém, seu interlocutor, com uma intenção, de uma determinada forma, numa dada situação. O texto como textualização do discurso é uma atividade coconstruída, efeito de sentidos entre interlocutores. $\mathrm{Na}$ concepção interacionista, a produção textual pressupõe um conteúdo interior que se projeta para o exterior pela expressão. O que temos, então? Um sujeito, com sua consciência, suas intenções, seus impulsos e seus gostos, que, pretendendo exteriorizar seu discurso, seu a-dizer, se transforma em autor. E o texto, o dito, é, por conseguinte, a ponte que permite ao leitor - o seu interlocutor - ter acesso ao discurso e ao sujeito que o produziu. Autor e leitor são dotados de uma memória discursiva presente no processo de produção e leitura do texto, um evento interpretativo, que contém já ditos que subjazem ao dito ou estão implícitos nele, evidenciando a interdiscursividade/intertextualidade. Nessa perspectiva, um mesmo texto admite a possibilidade de muitas leituras. Como a construção de sentido se faz na interação autor-leitor por meio do texto, o leitor é alçado ao status de autor - coautor ou coenunciador - do novo texto produzido com a leitura.
\end{abstract}

Palavras-chave: Produção textual. Interdiscurso. Ditos e não ditos. Interacionismo.

\footnotetext{
Pontifícia Universidade Católica de Minas Gerais (PUC Minas) . Doutor em Letras - Linguística e Língua Portuguesa. Professor Adjunto II. ORCID: https://orcid.org/0000-0002-2783-1467.
}

Cadernos CESPUC de Pesquisa. Série Ensaios. n.37, $2^{\circ}$ Sem./2020, p. 163-178. e-ISSN: 2358-3231 (OJS). Recebido em: 21/10/2020. Aceito em: 04/11/2020. 


\title{
The Texts a Text Hides...
}

\author{
Sérgio de Freitas Oliveira
}

\begin{abstract}
Reading and writing are interactive activities, since the writer does it with a purpose: to say something to someone, their interlocutor, with an intention, in a certain way, in a given situation. Text as speech textualization is a coconstructed activity, the effect of meanings between interlocutors. In the interactionist conception, textual production presupposes an interior content that projects itself outwards through expression. What do we have then? A subject, with his conscience, his intentions, his impulses and his tastes, who, intending to externalize his speech, his saying, becomes an author. And the text, the said, is, therefore, the bridge that allows the reader - his interlocutor - to have access to the discourse and the subject who produced it. Author and reader are endowed with a discursive memory present in the process of production and reading of the text, an interpretive event that already contains sayings that underlie or are implicit in it, highlighting interdiscursivity / intertextuality. From this perspective, the same text admits the possibility of many readings. As the construction of meaning is made in the authorreader interaction through the text, the reader is raised to the author status - coauthor or coenunciator - of the new text produced with reading.
\end{abstract}

Keywords: Text production. Interdiscourse. Said and unsaid. Interactionism.

Cadernos CESPUC de Pesquisa. Série Ensaios. n.37, $2^{\circ}$ Sem./2020, p. 163-178. e-ISSN: 2358-3231 (OJS). Recebido em: 21/10/2020. Aceito em: 04/11/2020. 
Escrever é uma ação que pressupõe a existência de um sujeito que tem algo a dizer e o faz em relação a um outro - seu interlocutor/leitor - com um certo propósito, ou seja, não se escreve simplesmente por escrever. Há sempre um outro, é uma relação $e u-t u$. Mesmo que o tu esteja apenas na imaginação, ou o tu seja o próprio eu, como no caso dos diários pessoais, em que o diálogo se faz com o próprio sujeito-autor. O princípio fundador da linguagem é, portanto, o dialogismo, dado que um enunciado sempre pressupõe o outro, é de alguém para alguém, é uma relação sujeitosujeito, como afirma Bakhtin (Volochínov), em Marxismo e Filosofia da linguagem (2014).

Ler e escrever é produzir sentido. E textos resultam de um trabalho intersubjetivo, são o lugar de interação e constituição de seus interlocutores. Eles apresentam versões de realidade construídas na atividade discursiva. Para compreendermos os processos de construção de sentido, tornamse imprescindíveis conhecimentos cognitivos e sociais envolvidos na organização, na produção, na compreensão e no funcionamento dos textos.

Nesse processo de produção de sentidos, cumpre-nos destacar a relação dos sujeitos com os textos no processo de leitura. Para Orlandi (2005b, p. 62), "O mesmo leitor não lê o mesmo texto da mesma maneira em diferentes momentos e em condições distintas de produção de leitura, e o mesmo texto é lido de maneiras diferentes em diferentes épocas, por diferentes leitores".

Para Coracini (2010), numa concepção interacionista, a leitura se processa na interação autor-texto-leitor. Dessa feita, concordamos com o que nos diz Orlandi (1988), citada por Coracini (2010, p. 18), que quem determina as leituras é o sujeito "enquanto participante de uma determinada formação discursiva, sujeito clivado, heterogêneo, perpassado pelo inconsciente, no qual se inscreve o discurso". Assim, "o leitor é o ponto de partida da produção do sentido", ele é o meio que nos permite identificar a produção do sentido, o dito e o não dito, como implícitos, pressupostos e subentendidos. O discurso é efeito de sentidos entre locutores, é uma "relação de sujeitos e sentidos afetados pela língua e pela história, [...] não meramente transmissão de informação" (ORLANDI, 2005a, p. 21), o que é ratificado por Matêncio (2013), ao afirmar ser a textualização uma atividade coconstruída por ações coordenadas dos sujeitos interactantes. 
E, por ser fruto de uma interação, o sentido do que se expressa é "um constructo, não podendo, por conseguinte, ser determinado a priori" (KOCH, 2015, p. 35). Como corrobora Possenti, o discurso é

um efeito de sentido, uma posição, uma ideologia - que se materializa através da língua. [...] o discurso se constitui pelo trabalho com e sobre os recursos de expressão, que produzem determinados efeitos de sentido em correlação com condições de produção específicas (POSSENTI, 1988, p. 160).

Canguilhem, citado por Pêcheux (1994, p. 62), afirma que "o sentido é relação $a$, o homem pode jogar com o sentido, desviá-lo, simulálo, mentir, armar uma cilada". É, portanto, a partir das relações propostas pelo enunciador que o sentido vai se construindo. Ainda, segundo o mesmo autor, a capacidade do homem de jogar com o sentido é decorrência da própria língua que lhe possibilita esse "jogo".

Para Pêcheux (1994, p. 63), "a leitura de um arquivo se faz na relação entre a língua, como sistema passível de jogo, e a discursividade, como inscrição de efeitos linguísticos materiais na história" (grifos do autor).

E Koch (2016, p. 7) ratifica dizendo que "a construção do texto exige a realização de uma série de atividades cognitivo-discursivas que, em seu inter-relacionamento, serão responsáveis pela produção de sentidos".

Sendo otexto, a materialização do discurso, ele deve, necessariamente, possibilitar ao interlocutor a construção do sentido pretendido pelo locutor. No entanto, um texto não tem uma única leitura, possibilita várias leituras, considerando, naturalmente, o interlocutor, aquele com quem interagimos. Segundo Possenti (2002):

[...] a questão da qualidade do texto passa necessariamente pela questão da subjetividade e de sua inserção num quadro histórico - ou seja, num discurso - que lhe dê sentido. O que se poderia interpretar assim: trata-se tanto de singularidade quanto de tomada de posição (POSSENTI, 2002, p. 115).

Bakhtin (Volochínov), em Marxismo e Filosofia da Linguagem, afirma ser a enunciação de natureza social (2014, p. 113). Segundo esse autor, ela se forma "no psiquismo do indivíduo, exterioriza-se para outrem com a ajuda de algum código de signos exteriores" (2014, p. 115). O que 
se evidencia com essa afirmação? A subjetividade, pois há um conteúdo interior que se projeta para o exterior pela expressão, e, obviamente, o primeiro lhe é anterior, embora sejam interdependentes.

Ora, se a enunciação é de natureza social, como afirmamos, ela pressupõe a existência de um interlocutor "pelo fato de que procede de alguém [...] e se dirige para alguém. [...] é produto da interação do locutor e do ouvinte" (BAKHTIN [VOLOCHÍNOV], 2014, p. 117, grifos do autor).

Então, o que temos? Um sujeito, um ser, um indivíduo com sua consciência, seus desejos, suas intenções, seus impulsos, seus gostos, que, pretendendo exteriorizar seu discurso, transforma-se em autor, a quem caberá textualizar esse discurso. O texto é, por conseguinte, a ponte que permite ao leitor ou ao ouvinte - o interlocutor - ter acesso ao discurso e ao sujeito que o produziu.

Analisemos um exemplo que pode ilustrar bem o processo de enunciação: a reportagem veiculada pela Revista Veja, de 29 de maio de 2019, de Thiago Bronzatto, intitulada "Aposta no tudo ou nada".

\section{Figura 1 - Capa da Revista Veja}

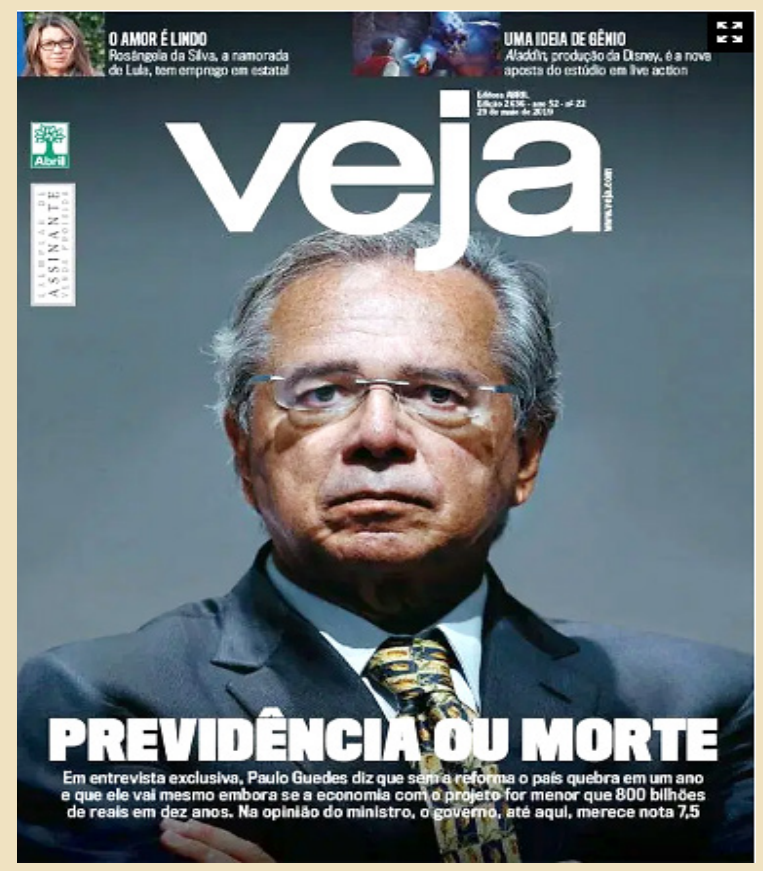

Fonte: Reproduzida pelo autor 


\section{O que temos na capa da revista?}

Temos um sujeito (o ministro da Economia Paulo Guedes) com sua consciência, seus desejos, suas intenções, seus impulsos, suas convicções, para quem "sem a reforma [da Previdência] o país quebra em um ano". Esse é o discurso do ministro [não do cidadão histórico, situado, Paulo Guedes]. Para exteriorizá-lo, interpretando-o, a Veja [assumindo a posição de autor] textualiza-o, com a expressão "Previdência ou morte", fazendo uma relação intertextual/interdiscursiva com a expressão que simboliza a Independência do Brasil, proclamada às margens do Rio Ipiranga, "Independência ou Morte!" [texto]. Observe-se que, na capa, temos uma assertiva, enquanto na Proclamação da República temos um grito, o Grito do Ipiranga, marcado na escrita pelo ponto de exclamação.

Sendo o texto a materialização linguística que nos permite ter acesso ao discurso, a intertextualidade evoca o interdiscurso. $\mathrm{Na}$ voz do enunciador, temos outra voz, e o novo texto surge num universo já povoado por outro texto, com o qual dialoga (GERALDI, 2010, p. 108). E o mesmo autor afirma que "as vozes mostradas num texto não são neutras e suas retomadas respondem a interesses discursivos do enunciador” (p. 109). Esse texto é o objeto que se apresenta ao leitor e ao analista do discurso, obviamente com objetivos distintos. Por ter sido "produzido por um sujeito interpelado ideologicamente", esse sujeito assume "a função enunciativa de autor", produzindo "seu texto a partir de um lugar social" (INDURSKY, 2001, p. 30).

O discurso expresso pelo texto em tela busca associar os dois eventos, a Independência do Brasil e a Reforma da Previdência, no intuito de transferir para a segunda a importância da primeira, que está registrada no imaginário do povo brasileiro. Este é o interdiscurso,

o conjunto de dizeres já ditos e esquecidos que determinam o que dizemos, sustentando a possibilidade mesma de dizer. Para que nossas palavras tenham sentido, é preciso que já tenham sentido. Esse efeito é produzido pela relação com o interdiscurso, a memória discursiva (ORLANDI, 2005b, p. 59).

Foucault, em A ordem do discurso, (1971, apud CORACINI, 2010, p. 17), é quem afirma que "o dizer é inevitavelmente habitado pelo já dito e se abre sempre para uma pluralidade de sentidos, que, por não 
se produzirem jamais nas mesmas circunstâncias, são, ao mesmo tempo, sempre e inevitavelmente novos".

$\mathrm{Na}$ concepção da Análise do Discurso, a heterogeneidade do discurso e do texto consiste na presença das palavras de outros sujeitos subjacentes às nossas palavras, como atestam Authier-Revuz e Pêcheux. $\mathrm{O}$ que isto quer dizer? Simplesmente que nossas palavras contêm um já dito por outros sujeitos, em outros discursos, em outros contextos, em outros espaços e em outros tempos, que lhe é constitutivo, ou seja, o nosso dizer é interdiscursivo, implica uma memória discursiva (INDURSKY, 2001, p. 28-29).

Esse texto é dirigido ao leitor da revista [interlocutor], que, por seu intermédio, alcança o discurso do ministro, para quem, se não houver a reforma da Previdência, o país quebra, entra em colapso (morre). Ou como expressa o título que o articulista dá ao texto, "Aposta no tudo ou nada".

Nessa reportagem, que se apoia numa entrevista com o ministro da Economia Paulo Guedes, o articulista inicia o texto (p. 44) com uma narrativa que a contextualiza. Ele se desloca para o passado, "No fim do ano passado, logo depois das eleições", para expressar uma expectativa futura nesse passado [futuro do pretérito], que não se concretiza. O narrador, no presente, relata fato passado concluído, encerrado, "o futuro ministro da Economia procurou" [pretérito perfeito do indicativo]. Era, na época, um objetivo: "o presidente usaria", "o novo governo ganharia [...], pouparia". Há outras marcações temporais, como "já anunciado, antes mesmo da sua posse, nos estertores da administração, em fim de mandato, seis meses depois", "Lá na frente". Na construção do texto, o autor recorre, ainda, a outros mecanismos enunciativos e de textualização, como propõe Bronckart (2012, cap. 4 e 7 ) ao tratar da arquitetura interna do texto, com o propósito de demonstrar para o leitor a urgência e a importância da reforma para corrigir desigualdades, evitar o caos e impulsionar o crescimento.

A construção de sentido é feita pela comparação, pela oposição, pelo contraste, como no quadro a seguir. De um lado, a salvação, a redenção (a Reforma da Previdência). De outro, as trevas, o caos, a morte. 
Quadro 1 - Argumentos apresentados na reportagem "Previdência ou morte"

\begin{tabular}{|c|c|c|}
\hline Previdência ("Independência") & ou & Morte \\
\hline 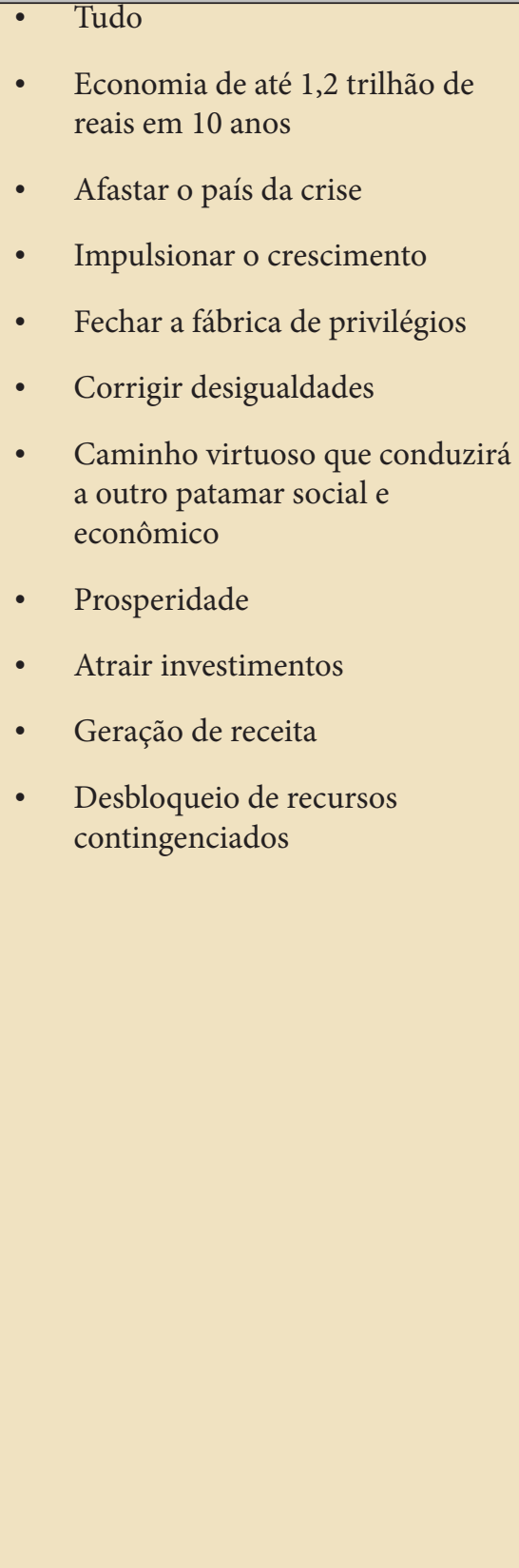 & & 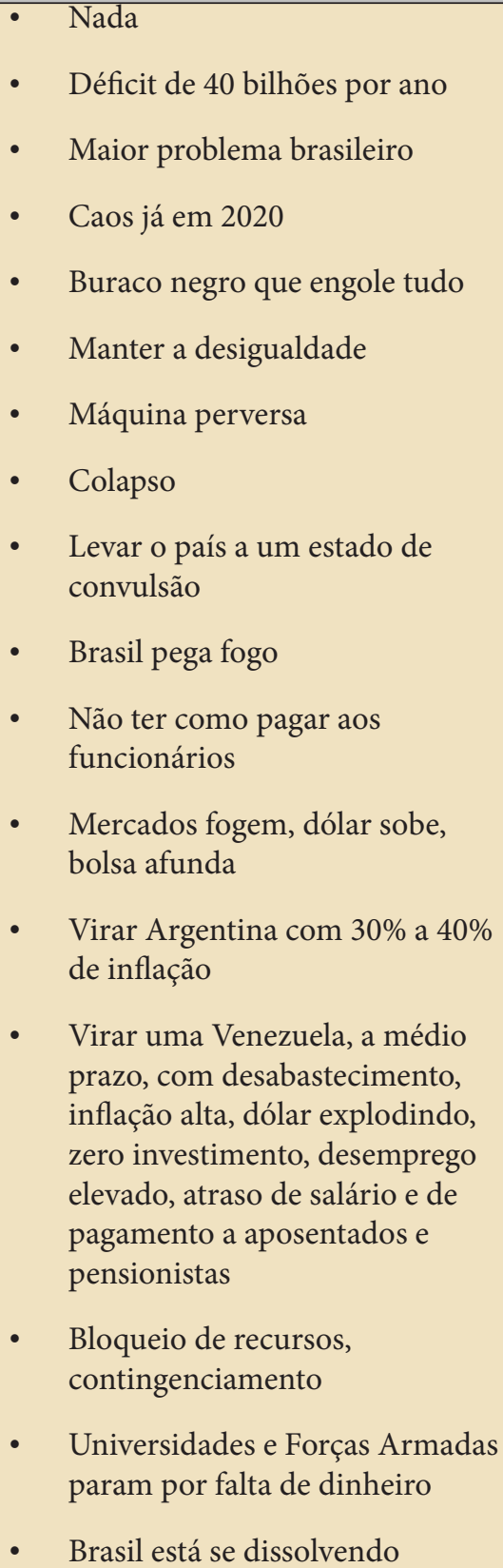 \\
\hline
\end{tabular}

Fonte: Elaborado pelo autor 
Os temas tratados na entrevista são apresentados em forma de assertivas, em fonte condensada, não em forma de perguntas e respostas. Estas são reproduzidas em discurso direto, entre aspas.

Tomemos, agora, para análise, a capa da revista Super Interessante, de julho de 2019.

\section{Figura 2 - Capa da Revista Super Interessante}

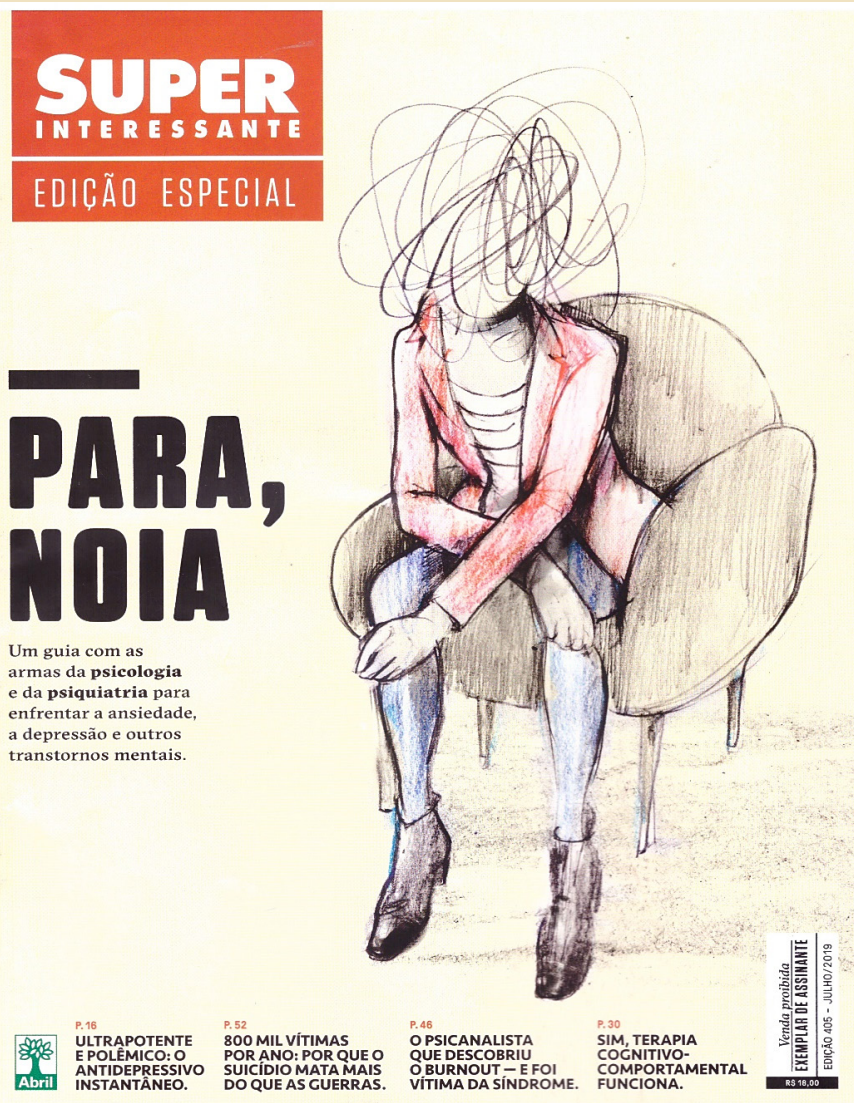

Fonte: Reproduzida pelo autor

A chamada da capa dessa edição especial da revista é para o tema "Paranoia". Consultando dicionários, "paranoia" é um termo genérico empregado na Psiquiatria e na Psicologia referindo-se a problemas psíquicos, distúrbios mentais ou perturbações caracterizados por desconfiança obsessiva ou delírios de uma pessoa, decorrentes da sensação 
de que alguém a está perseguindo, ou tentando prejudicá-la, de que está sendo traída, provocando-lhe crises descontroladas de ciúme, ou ainda de que está sempre sendo criticada por alguém que se imagina não gostar dela (HOUAISS, 2001, p. 2130).

Etimologicamente, a palavra é de origem grega e significa "loucura; turvamento da razão" (HOUAISS, 2001, p. 2130).

$\mathrm{Na}$ análise da composição dessa palavra, identificamos na sua formação dois elementos: "para" e "noia", que podemos entender como "lutar ou guerrear contra" e "a razão, a compreensão e o entendimento".

Popularmente, ela é usada com frequência na sua forma reduzida "noia", que, de parte, passa a significar o todo, ou seja, o sentido da palavra desliza para o segundo elemento de sua composição.

Na reportagem de capa da revista (BOTELHO, 2019), localizamos quatro citações sobre as implicações dessa doença, que contribuem para a construção do já dito na memória discursiva das pessoas e para a compreensão dos sentidos dessa chamada:

"320 milhões de pessoas sofrem depressão em todo o mundo, de acordo com um relatório de 2017 da Organização Mundial da Saúde (OMS)” (p. 20).

"No Brasil, 5,9\% da população tem depressão" (p. 24).

"Segundo dados de 2017 da Organização Mundial da Saúde (OMS), a depressão cresceu em 15\% desde 2007 e deve se tornar a doença mais incapacitante do planeta" (p. 25).

"A cada duas pessoas com depressão, apenas uma procura ajuda" (p. 28).

Por que toda essa contextualização? Para entendermos o jogo de sentido presente na capa, cujo texto verbal permite ao leitor mais de uma leitura. A imagem, como linguagem não verbal, ilustra e compõe o propósito do sujeito-autor na produção do discurso.

Numa primeira leitura, podemos imaginar que a reportagem tratará da "paranoia", não enxergando a vírgula ou interpretando-a como separação de sílaba, por não caber na linha, já que há uma figura ilustrando a capa. 
Uma segunda leitura, esta mais acurada, nos mostra um outro texto, um intertexto, em que a composição da palavra se transforma em uma frase: o primeiro elemento passa a ser um verbo [parar], na forma imperativa, segunda pessoa do singular, e o segundo, um substantivo, na forma reduzida, na condição de vocativo. O enunciador, com essa frase, dirige-se "à noia" ordenando-lhe "que pare". "Noia", nesse caso, é um ente personificado [+ animado], imaginado com capacidade para executar a ordem que lhe é apresentada.

Uma terceira leitura poderia ser com o "para" na função de preposição, indicando que a matéria da revista se destina ou é endereçada "à noia" ou a tem como finalidade. Ou ainda, a preposição no sentido de "combate a, contra a", como em "para enxaqueca". Essa terceira leitura fica ratificada no texto que vem logo abaixo, dizendo tratar-se de "um guia" para tratamento da doença. Voltando ao sentido do primeiro termo da composição da palavra, "para" [lutar ou guerrear contra], identificamos um modo de dizer que lhe é coerente: "um guia [um roteiro] com armas [...] para enfrentar [...] (grifos nossos)".

Nesse jogo, percebemos um deslizamento de sentidos nos discursos presentes no texto, uma interdiscursividade/intertextualidade, reforçando a ideia de que o leitor é coenunciador, produzindo outros textos, de acordo com a leitura que faz.

O texto, permitindo as várias leituras, materializa diversos discursos que, intencionalmente ou não, lhe subjazem, sendo apreendidos pelo leitor ao interagir com ele. Há, portanto, não ditos que se revelam pelo dito, que emergem do imaginário do leitor ao se deparar com o texto que se lhe apresenta.

Possenti (2001, p. 24) afirma que "Leitura não é a leitura de um texto como texto, mas como discurso, isto é, na medida em que é remetido às suas condições, principalmente institucionais, de produção”. Em outra passagem, esse autor diz que "Ler deveria ser, antes de mais nada, desmontar um texto para ver como ele se constrói, até para que se possa dizer qual a relação entre seu modo de ser construído e os efeitos de sentido que produz" (POSSENTI, 2002, p. 106). Desmontá-lo para desvelar seu modo de produção e sua intencionalidade.

Como preconiza o método indiciário, na interação com o texto, o leitor, numa perspectiva ativa e crítica, rastreia implícitos, pressupostos, 
lacunas e subentendidos, realizando um trabalho discursivo na produção dessa leitura, como que desmontando ou desconstruindo o efeito-texto, construindo novos sentidos. Nesse "trabalho discursivo de reestruturação do texto produzido pelo trabalho discursivo da leitura, o texto é ressignificado, dele resultando a reconstrução de um novo efeito-texto" (INDURSKY, 2001, p. 39-40).

Nesse processo de leitura, o sujeito-leitor emerge como um sujeitoautor, respondendo por um novo efeito-texto, ressignificado por sua leitura. Para Koch (2016, p. 18), “O ouvinte [leitor] não se limita a 'entender' o texto no sentido de captar seu conteúdo referencial, mas atua no sentido de reconstruir os propósitos do falante [escrevente] ao estruturá-lo, isto é, descobrir o 'para quề do texto”, pois “o sentido não está no texto, mas se constrói a partir dele, no curso da interação" (p. 30, grifos da autora). A materialidade do texto é a menor parte, o que está exposto, explícito. Muito mais está implícito, infere-se, lê-se nas entrelinhas.

E sobre o processo de leitura, Leffa (1999, p. 14) destaca que o significado não é extraído do texto, mas atribuído a ele pelo leitor. "O leitor transaciona com o autor através do texto, num contexto específico, com intenções específicas", como nos diz Goodman (1994, p. 814, citado por Leffa, 1999, p. 30).

Na concepção interacionista, o autor, na produção de seu texto, não pode pensar apenas no que e no como escrever. Ele precisa levar em conta o para quem, o seu interlocutor. Este é parte constitutiva do processo de escrita.

$\mathrm{Na}$ concepção interacional (dialógica) da língua, tanto aquele que escreve como aquele para quem se escreve são vistos como atores/construtores sociais, sujeitos ativos que - dialogicamente - se constroem e são construídos no texto como evento comunicativo (KOCH; ELIAS, 2015, p. 34, grifos das autoras).

O que é corroborado por Leffa, quando afirma:

O autor muda na medida em que vai escrevendo o texto, muda o leitor na medida em que vai lendo e muda o texto, tanto durante a escrita como durante a leitura. O texto, em outras palavras, é construído não só pelo autor ao produzi-lo, mas também pelo leitor ao lê-lo (LEFFA, 1999, p. 30-31). 
Como a construção do sentido se faz na interação autor/leitor, podemos dizer que o leitor é o autor do novo texto que se produz com a leitura, o que elevaria o leitor ao status de coautor, dado que a leitura é um processo discursivo, em que autor e leitor são produtores de sentido.

O leitor não apenas se constitui por suas leituras, mas está presente no próprio processo de produção do texto (objeto de leitura) que seja lido, e enquanto leitor virtual, ele é coenunciador do texto. Enquanto leitor real, ele é o enunciador dos sentidos que construiu em sua leitura, e o outro (o autor) passa, neste momento, a coenunciador de sua leitura (GERALDI, 2010, p. 106-107).

No processo interativo de leitura, identificamos o leitor como coprodutor do texto objeto da leitura. É como se, ao ler, o leitor fosse escrevendo um novo texto. Nesse processo de coprodução, o leitor como coenunciador assume uma posição autoral.

Ler um arquivo textual hoje, usando uma expressão empregada por Pêcheux, inclui e implica as contrapalavras do leitor no processo de construção do sentido concreto, produto da leitura que atualiza o texto enunciado num novo contexto, numa nova situação.

Assim, a leitura, por produzir sentido, é coprodução de um texto, parte dele, mas vai além dele, caracterizando-se o leitor como coenunciador, num processo de interação.

Lendo, o leitor produz significações e, nesse sentido, vai se constituindo como leitor. Autor, texto e leitor não preexistem, se constroem concomitantemente. $\mathrm{O}$ autor se faz enquanto escreve; o texto se constrói enquanto é escrito; o leitor se constitui enquanto lê, na relação com a linguagem, em função da textualidade.

No texto, "há um querer dizer do enunciador, um projeto de dizer que orienta a materialização textual. Este querer dizer inscreve-se na ordem da materialidade do discurso de que o texto é a materialização superficial" (GERALDI, 2003, p. 107, grifos nossos). Por meio do texto disponibilizado pelo enunciador ao leitor, seu interlocutor, este chega ao discurso (ou aos discufsos) que o texto materializa.

Um texto, como manifestação de um discurso, tem seu sentido constituído na relação entre o que se diz e o que não se diz, o dito e o não dito. Ou seja, mesmo não estando escritos ou expressos no texto, os não 
ditos ou implícitos significam e são importantes na compreensão do texto como forma de acesso ao discurso. Como costumamos dizer, é preciso ler nas entrelinhas. Ou como nos ditados populares: "Para um bom entendedor, meia palavra basta", ou "Para um bom entendedor, pingo é letra".

Os sentidos ultrapassam o que está explícito no texto. Segundo Pêcheux (1977), o sentido das palavras está na formação discursiva em que são produzidas. Para o autor, esta determina o que "pode" e "deve" ser dito. Por conseguinte, é nas entrelinhas que se encontra a formação discursiva.

Os implícitos ou não ditos de um discurso expressam a sua incompletude. Para Orlandi (1992, p. 12), “[...] há uma dimensão do silêncio que remete ao caráter de incompletude da linguagem: todo dizer é uma relação fundamental com o não dizer".

Dessa feita, a prática de leitura implica a relação do que se diz num discurso com o que é dito em outros. Foucault, em A ordem do discurso (1971 apud CORACINI, 2010, p. 17), afirma que "o dizer é inevitavelmente habitado pelo já dito e se abre para uma pluralidade de sentidos, que, por não se produzirem jamais nas mesmas circunstâncias, são, ao mesmo tempo, sempre e inevitavelmente novos. Há um não dito naquilo que é dito. “Todo enunciado está intrinsecamente exposto ao equívoco da língua, sendo, portanto, suscetível de tornar-se outro" (PÊCHEUX, 1982, apud ORLANDI, 2005b, p. 60) e esse lugar do outro enunciado é lugar da interpretação.

Por isso, para interpretar e compreender um texto, o leitor precisa relacioná-lo com o interdiscurso de que sua leitura necessita. Retomamos, aqui, a capa da Revista Veja, anunciando a questão da Reforma da Previdência, numa entrevista com o ministro da Economia, Paulo Guedes: "Previdência ou morte", e a capa da Revista Super Interessante, que remete a uma matéria sobre "Paranoia".

Segundo Orlandi, trata-se de uma leitura discursiva e não de texto, matéria que se coloca diante do leitor. A leitura discursiva

[...] consiste em considerar o que é dito em um discurso e o que é dito em outro, o que é dito de um modo e o que é dito de outro modo, procurando escutar o não dito naquilo que é dito, como uma presença de uma ausência necessária [...] porque [...] só uma parte do dizível é acessível ao sujeito, pois, mesmo o que ele não diz (e que muitas vezes ele desconhece), significa em suas palavras (ORLANDI, 2005a, p. 34). 


\section{Referências}

BAKHTIN, M. (VOLOCHÍNOV, V. N.). Marxismo e Filosofia da Linguagem. Problemas fundamentais do método sociológico na ciência da linguagem. Tradução Michel Lahud e Yara Frateschi Vieira. 16. ed. São Paulo: Hucitec, 2014. 203 p. (Linguagem e cultura; 3).

BOTELHO, J. F. O enigma dos antidepressivos. Super Interessante, Editora Abril, n. 405, jul. 2019, Edição Especial, p. 16-29.

BRONCKART, Jean-Paul. Atividade de linguagem, textos e discursos. Por um interacionismo sociodiscursivo. Tradução Anna Rachel Machado e Péricles Cunha. 2. ed. 2. reimpr. São Paulo: EDUC, 2012. 353 p.

CORACINI, M. J. R. F. Leitura: decodificação, processo discursivo...? In: CORACINI, M. J. R. F. (org.). O jogo discursivo na aula de leitura: língua materna e língua estrangeira. Campinas (SP): Pontes, 2010. p. 13-20.

GERALDI, J. W. (org.). O texto na sala de aula. 3. ed. São Paulo: Ática, 2003. $136 \mathrm{p}$.

GERALDI, J. W. A leitura e suas múltiplas fases. In: GERALDI, J. W. Aula como acontecimento. São Carlos (SP): Pedro \& João, 2010. p. 103-112.

HOUAISS, A. Dicionário Houaiss da Língua Portuguesa. Rio de Janeiro: Ed. Objetiva, 2001.

INDURSKY, F. Da heterogeneidade do discurso à heterogeneidade do texto e suas implicações no processo de leitura. In: LEFFA, V. J. (org.). A leitura e a escrita como práticas discursivas. Pelotas (RS): Educat, 2001. p. 27-42, 2001.

INDURSKY, F. O texto nos estudos da linguagem: especificidades e limites. In: ORLANDI, E. P.; LAGAZZI-RODRIGUES, S. Discurso e textualidade. Campinas (SP): Pontes, 2006. p. 33-80.

KOCH, I. V. Desvendando os segredos do texto. 8. ed. São Paulo: Cortez, 2015.

KOCH, I. V. O texto e a construção dos sentidos. 10. ed. 4. reimp. São Paulo: Contexto, 2016. 
KOCH, I. V.; ELIAS, V. M. Ler e escrever: Estratégias de produção textual. 2. ed. 3. reimp. São Paulo Contexto, 2015.

LEFFA, V. J. Perspectivas no estudo da leitura: texto, leitor e interação social. In: LEFFA, V. J.; PEREIRA, A. E. (org.). O ensino da leitura e produção textual: alternativas de renovação. Pelotas (RS): Educat, 1999. p. 13-37.

MATENCIO, M. L. Práticas discursivas. In: BUENO, L.; LOPES, M. A. P. T.; CRISTÓVÃO, V. L. L. (org.). Gêneros e formação inicial. Uma homenagem a Malu Matencio. São Paulo: Mercado das Letras, 2013. Cap. 3.

ORLANDI, E. P. Análise do discurso: princípios e procedimentos. 5. ed. Campinas (SP): Pontes, 2005a.

ORLANDI, E. P. As formas do silêncio: no movimento de sentidos. Campinas (SP): Ed. da Unicamp, 1992.

ORLANDI, E. P. Os efeitos de leitura na relação discurso/texto. In: ORLANDI, E. P. Discurso e texto: formulação e circulação dos sentidos. Campinas (SP): Pontes, 2005b. p. 59-71.

ORLANDI, E. P; GUIMARÃES, E. Unidade e dispersão: uma questão do texto e do sujeito. In: ORLANDI, E. P. Discurso e leitura. São Paulo: Cortez, 1988.

PÊCHEUX, M. Análise automática do discurso. In: GADET, F.; HAK, T. Por uma análise automática do discurso: uma introdução à obra de $\mathrm{M}$. Pêcheux. Campinas (SP): Ed. da Unicamp, 1997. p. 61-105.

PÊCHEUX, M. Ler o arquivo hoje. In: ORLANDI, E. P. Gestos de leitura: da história no discurso. Campinas (SP): Ed. da Unicamp, 1994, p. 55-64.

POSSENTI, S. Discurso, estilo e subjetividade. São Paulo: Martins Fontes, 1988.

POSSENTI, S. Indícios de autoria. Perspectiva, Florianópolis, v. 20, n. 1, p. 105-124, jan./ jun. 2002, Disponível em: https://periodicos.ufsc.br/index. php/perspectiva/article/view/10411 Acesso em: 05 jul. 2019.

POSSENTI, S. Sobre a leitura: o que diz a análise do discurso. In: MARINHO, M. (org.). Ler e navegar: espaços e percursos da leitura. Campinas (SP): Mercado de Letras, 2001. p. 19-30. 